\title{
ISOLAMENTO E SELEÇÃO DE RIZOBACTÉRIAS PROMOTORAS DO CRESCIMENTO DE Pinus taeda ${ }^{1}$
}

\author{
Juliana Margarido Fonseca Couto Brunetta², Acelino Couto Alfenas ${ }^{3}$, Reginaldo Gonçalves Mafia ${ }^{4}$, \\ José Mauro Gomes ${ }^{3}$, Daniel Breda Binoti ${ }^{4}$ e Nilva Aparecida Nicolao Fonseca ${ }^{5}$
}

\begin{abstract}
RESUMO - Este trabalho teve como objetivos isolar e selecionar rizobactérias promotoras do crescimento de $P$. taeda. O isolamento foi realizado a partir de mudas com 150 dias de idade, realizando-se a seleção por meio da inoculação dos isolados $\left(10^{8}\right.$ u.f.c $\left.\mathrm{mL}^{-1}\right)$ na proporção de $0,1 \mathrm{~mL}$ de inóculo.cm ${ }^{-3}$ de substrato. Aos 150 dias de semeadura, avaliaram-se as seguintes variáveis: altura da parte aérea, diâmetro do coleto e pesos de matéria seca de raízes e da parte aérea. Entre 99 isolados testados em P. taeda, apenas seis (UFV-AL9, UFV-AM5, UFV-AM2, UFV-F3, UFV-G2 e UFV-G4) destacaram-se quanto à indução de crescimento e ao melhor índice de qualidade de muda. Não se observaram diferenças significativas entre a testemunha e os demais isolados testados.
\end{abstract}

Palavras-chave: Pinu, Rizobactérias e Qualidade de mudas.

\section{ISOLATION AND SELECTION OF Pinus taeda GROWTH PROMOTING RHIZOBACTERIA}

\begin{abstract}
The objectives of this research were to isolate and select P. taeda growth promoting rhizobacteria. The bacteria were isolated from 150 day-old pine seedlings and the selection was carried out with the strains inoculation $\left(10^{8}\right.$ u.f.c $\left./ \mathrm{mL}\right)$ in the proportion of $0.1 \mathrm{~mL} / \mathrm{cm}^{3}$. After 150 days of sowing, aerial part height, stem diameter and roots and aerial part dry matter weight were evaluated. From the 99 tested strains, six (UFVAL9, UFV-AM5, UFV-AM2, UFV-F3, UFV-G2 and UFV-G4) stood out due to their capacity of stimulating the growth and quality improvement of P. taeda seedlings. Significant differences were not observed between the control and the other tested strains.
\end{abstract}

Keywords: Pinus, Rhizobacterias and Seedling quality.

\section{INTRODUÇÃO}

Os plantios florestais com espécies de rápido crescimento ocupam, no Brasil, aproximadamente 4,8 milhões de hectares, dos quais cerca de 1,87 milhão de hectares correspondem a espécies de Pinus (ABRAF, 2009). A madeira oriunda desses plantios tem sido utilizada para produção de carvão, celulose, compensados, aglomerados, chapas de fibras e painéis, entre outros. Diante da crescente demanda de madeira e da importância econômica do setor, torna-se necessário otimizar as diferentes fases da cadeia produtiva de Pinus, incluindo a produção de mudas (CARNEIRO, 1995). Nesse sentido, é fundamental desenvolver formas alternativas, visando reduzir o tempo de produção e melhorar a qualidade das mudas. Estas devem apresentar características que possam oferecer certa resistência às condições climáticas adversas que poderão ocorrer no pós-plantio, mesmo que este tenha sido efetuado em condições favoráveis de umidade do solo (FONSECA, 2002).

Estudos recentes comprovaram o efeito benéfico da aplicação de rizobactérias em substrato de produção de mudas sobre o enraizamento, o crescimento e o biocontrole de doenças do eucalipto (TEIXEIRA, 2001; MAFIA et al., 2005; TEIXEIRA et al., 2005). A região

\footnotetext{
${ }^{1}$ Recebido em 15.01.2007 e aceito para publicação em 02.03.2010.

${ }^{2}$ Progama de Pós-Graduação em Ciência Florestal na Universidade Federal de Viçosa, Brasil. E-mail: <juliana.brunetta@uol.com.br>.

${ }^{3}$ Universidade Federal de Viçosa, UFV, Brasil. E-mail: <aalfenas@ufv.br>.

${ }^{4}$ Aracruz Celulose S.A., Aracruz, Brasil.

${ }^{5}$ Universidade Estadual de Londrina, UEL, Brasil.
} 
do solo, ou substrato, sob a influência do sistema radicular das plantas, definida como rizosfera, é intensamente colonizada por vários microrganismos, sendo as bactérias que colonizam essa região denominadas rizobactérias (SCHROTH; HANCOCK, 1982). As rizobactérias interagem com as raízes (KUNC; MACURA, 1988), o que pode resultar em efeito benéfico, prejudicial ou neutro à planta. Bactérias que beneficiam são denominadas "rizobactérias promotoras do crescimento de plantas", pois são capazes de colonizar as raízes e estimular o crescimento, quando aplicadas na rizosfera, nos tubérculos ou em sementes (KLOEPPER et al., 1989).

Em experimentos com várias espécies de Pinus, constataram-se aumento no crescimento e desenvolvimento de mudas (CHANWAY et al., 2000), colonização do sistema radicular (BENT et al., 2002), indução de resistência sistêmica a doença (ENEBAK; CAREY, 2004) e alteração nos níveis hormonais e na respiração de raízes inoculadas com rizobactérias (BENT et al., 2001).

Neste trabalho, objetivaram isolar e selecionar rizobactérias com potencial para utilização na produção de mudas de $P$. taeda L., visando aumentar o crescimento e a qualidade de mudas.

\section{MATERIAL E MÉTODOS}

\subsection{Isolamento de rizobactérias}

Foram realizados isolamentos de rizobactérias da rizosfera e de segmentos radiculares de mudas de $P$. taeda cultivadas em tubetes cônicos de $50 \mathrm{~mL}$, com 150 dias de idade, oriundos de Telêmaco Borba (PR) e de Mogi-Guaçu (SP). Para isso, cerca de $1 \mathrm{~g}$ de substrato rizosférico e de segmentos radiculares foi colocado em erlenmeyers contendo $20 \mathrm{~mL}$ de água destilada esterilizada. Após agitação por 40 seg, em minishaker a 1.000 rpm, a suspensão foi filtrada em camada dupla de gaze esterilizada.

Realizou-se então, em tubos de ensaio, a diluição seriada na razão de 1:10 do filtrado até a diluição $1 \times 10^{-5}$, procedendo-se à transferência de $1 \mathrm{~mL}$ das três últimas diluições em meio B de King (KING et al., 1954). Na sequência, os mesmos tubos de ensaio contendo as três últimas diluições foram aquecidos a $80{ }^{\circ} \mathrm{C}$ e mantidos nessa temperatura, em banho-maria, por 20 min, antes da transferência de $1 \mathrm{~mL}$ para meio de Kado e Heskett (1970), para isolamento seletivo de Bacillus spp.

Revista Árvore, Viçosa-MG, v.34, n.3, p.399-406, 2010
Para purificar as colônias com diferentes características morfológicas, após a incubação por 24 h a $28{ }^{\circ} \mathrm{C}$, no escuro, elas foram repicadas por três vezes e, então, transferidas individualmente para tubos de ensaio contendo meio de Kado e Heskett inclinado e armazenadas a $5^{\circ} \mathrm{C}$.

\subsection{Seleção dos isolados de rizobactérias}

Para seleção dos isolados foram conduzidos quatro ensaios independentes no viveiro de Pesquisa do Departamento de Engenharia Florestal da UFV, em ViçosaMG, sendo um instalado em abril, outro em agosto e dois em setembro de 2004.

As sementes de P. taeda (procedentes da APS - Telêmaco Borba/Klabin Florestal S.A.) empregadas no ensaio foram previamente submetidas à quebra de dormência, por meio da estratificação em areia umedecida a $10{ }^{\circ} \mathrm{C}$, por 26 dias.

Para produção de inóculo, cada isolado de rizobactéria foi cultivado, separadamente, em placa de Petri com meio recomendado por Kado e Heskett (1970). Após a incubação por 24 h a $28{ }^{\circ} \mathrm{C}$, no escuro, procedeu-se à raspagem do crescimento das rizobactérias, utilizando-se solução salina ( $\mathrm{NaCl}, 0,85 \%)$. A densidade ótica de cada suspensão foi ajustada para 0,2 de absorbância em 540 nm, o que corresponde, aproximadamente, a $10^{8}$ u.f.c./mL, conforme correlação entre densidade ótica e número de unidades formadoras de colônias (ufc), com base em Teixeira (2001).

O inóculo foi aplicado ao substrato de produção de mudas (Plantmax ${ }^{\circledR}$ ), na proporção de $0,1 \mathrm{~mL} / \mathrm{cm}^{3}$ de substrato antes da semeadura, em tubetes de $50 \mathrm{~cm}^{3}$. Os substrato umedecido com solução salina, autoclavada na mesma proporção, serviu como testemunha. Além da inoculação com os isolados de rizobactérias, realizou-se a aplicação de acículas picadas de Pinus, como fonte inicial de fungos micorrízicos, antes do plantio, na proporção de 1:6 (p/p).

Os experimentos foram conduzidos em delineamento inteiramente casualizado, composto de cinco repetições por tratamento, sendo cada parcela constituída de 20 mudas. Os tratamentos constaram da inoculação de mudas de $P$. taeda cultivadas em tubetes com $50 \mathrm{~cm}^{3}$ de substrato comercial Plantmax ${ }^{\circledR}$, com cada um dos isolados de rizobactéria, separadamente. Foi mantido um controle sem inoculação. 
A semeadura foi realizada diretamente nos tubetes, e aos 20 dias realizou-se o raleio, deixando apenas uma muda vigorosa no centro de cada tubete. Os tubetes foram mantidos inicialmente em casa de sombreamento (50\% de luminosidade natural), acondicionados em bandejas planas com capacidade para 1.200 tubetes, suspensas a $80 \mathrm{~cm}$ do solo. Imediatamente após o raleio das plântulas, estas foram transferidas para casa de vegetação coberta com lona plástica transparente e com abertura lateral.

A ocupação das bandejas nos primeiros 30 dias foi de $100 \%$, deixando-se apenas uma linha vazia entre cada repetição; após esse período, as mudas foram espaçadas, para capacidade de 50\%.

A irrigação das mudas e os demais tratos culturais foram realizados conforme recomendações específicas para produção de mudas de pinus.

A adubação de base do substrato foi feita com 10 kg de NPK (20-0-20) e 4 kg de Fosmag 400 ${ }^{\circledR}$ (fosfato magnesiano) por $\mathrm{m}^{3}$ de substrato. A adubação de formação iniciou-se aos 10 dias após a operação de raleio, em intervalos de 15 dias, com aplicação de $5 \mathrm{~mL}$ de solução, contendo $25 \mathrm{~kg}$ de superfosfato simples, $11 \mathrm{~kg}$ de sulfato de amônia e 5 kg de cloreto de potássio em 1.000 L de água.

\subsection{Avaliações, delineamento experimental e análises estatísticas}

Aos 150 dias após a semeadura, avaliaram-se a altura da parte aérea e o diâmetro do coleto, bem como o peso de matéria seca de raízes e da parte aérea. A determinação da matéria seca foi realizada após a separação da parte aérea do sistema radicular e secagem em estufa a 70 ${ }^{\circ} \mathrm{C}$, por $24 \mathrm{~h}$. Os dados da altura da parte aérea (APA), do diâmetro do coleto (DC) e do peso de matéria seca de raízes (PMSR) e da parte aérea (PMSPA) foram empregados para cálculo do índice de qualidade de Dickson (IQD), definido por Dickson et al. (1960).

\section{$I Q D=(P M S P A+P M S R) /((A P A / D C)+(P M S P A / P M S R))$}

em que:

APA = altura da parte aérea da muda, do colo até a ponta do broto mais alto $(\mathrm{cm})$;

$D C=$ diâmetro do coleto (na altura do colo da planta) (mm);

PMSR = peso de matéria seca de raízes (g); e

PMSPA = peso de matéria seca da parte aérea (g).
Os experimentos de seleção de isolados foram conduzidos em delineamento inteiramente casualizado, compostos de cinco repetições por tratamento, cada uma constituída de 20 unidades amostrais. Os dados de cada ensaio foram submetidos à análise de variância (ANOVA), aplicando-se o teste $\mathrm{F}$ a $5 \%$ de probabilidade, e as médias foram comparadas pelo teste de ScottKnot (5\% de probabilidade), com o auxílio do programa SAEG (EUCLYDES, 1983).

Os dados de cada ensaio foram submetidos à análise de variância (ANOVA), aplicando-se o teste F a 5\% de probabilidade, sendo as médias comparadas pelo teste de Scott-Knot (5\% de probabilidade), com o auxílio do programa SAEG (EUCLYDES, 1983).

\section{RESULTADOS E DISCUSSÕES}

Na primeira etapa do trabalho, obtiveram-se 196 isolados de rizobactérias, com uma média de cinco isolados por planta, oriundas de 20 amostras de raízes. Os isolados apresentaram grande variação quanto à morfologia da colônia, incluindo consistência, elevação, cor, velocidade e forma de crescimento. Esses isolados se encontram devidamente identificados e armazenados a $5{ }^{\circ} \mathrm{C}$, no Departamento de Fitopatologia da Universidade Federal de Viçosa, em Viçosa - Minas Gerais.

A seleção dos melhores isolados foi baseada na altura da parte aérea das mudas, juntamente com o índice de qualidade de Dickson.

Em quatro seleções, utilizando-se 99 das rizobactérias isoladas, constatou-se que houve efeito benéfico da inoculação sobre o crescimento das mudas, julgando-se pelos incrementos observados na altura da parte aérea e no peso de matéria seca de raízes e da parte aérea, bem como sobre a qualidade, definida pelo índice de qualidade de Dickson.

Na primeira seleção, não houve diferença significativa da altura da parte aérea e do diâmetro de coleto em função da inoculação das rizobactérias. No entanto, quatro (UFV-E2, UFV-F4, UFV-C4 e UFVB3) dos 26 isolados utilizados nesse mesmo ensaio induziram ao incremento do peso de matéria seca da parte aérea, e oito (UFV-F4, UFV B3, UFV-D6, UFVE2, UFV-F9, UFV-A3, UFV-E6 e UFV-C4) promoveram aumento do peso de matéria seca do sistema radicular de P. taeda (Tabela 1 ).

Revista Árvore, Viçosa-MG, v.34, n.3, p.399-406, 2010 
Tabela 1 - Média da altura da parte aérea (APA), diâmetro do coleto (DC), peso de matéria seca da parte aérea (PMSPA) e de raízes (PMSR) e índice de qualidade de Dickson (IQD) do primeiro ensaio de seleção de mudas de $P$. taeda aos 150 dias de semeadura.

Table 1 - Aerial part height, stem diameter, aerial part and root dry matter weight and Dickson quality index averages of $\boldsymbol{P}$. taeda seedlings first selection assay, 150 days after sowing.

\begin{tabular}{|c|c|c|c|c|c|}
\hline solado & $\begin{array}{l}\text { APA } \\
(\mathrm{cm})\end{array}$ & $\begin{array}{c}\mathrm{DC} \\
(\mathrm{mm})\end{array}$ & $\begin{array}{c}\text { PMSPA } \\
\text { (g) }\end{array}$ & $\begin{array}{c}\text { PMSR } \\
\text { (g) }\end{array}$ & $\bar{D}$ \\
\hline V-D9 & 13,5 a & $32 \mathrm{a}$ & $0,54 \mathrm{~b}$ & $0,33 \mathrm{~b}$ & 110 \\
\hline FV-D4 & $14,0 \mathrm{a}$ & $2,43 \mathrm{a}$ & 59 b & $0,37 \mathrm{~b}$ & 131 \\
\hline FV-B5 & 13,5 a & $2,47 \mathrm{a}$ & $57 \mathrm{~b}$ & $0,35 \mathrm{~b}$ & 132 \\
\hline FV-D6 & 13,5 a & $2,51 \mathrm{a}$ &, $54 \mathrm{~b}$ & 0,43 a & 147 \\
\hline FV-F10 & 13,5 a & $2,40 \mathrm{a}$ &, $56 \mathrm{~b}$ & $0,37 \mathrm{~b}$ & , 1318 \\
\hline FV-F2 & 13,5 a & $2,33 \mathrm{a}$ &, $57 \mathrm{~b}$ & $0,36 \mathrm{~b}$ & 1298 \\
\hline 3 & 13,5 a & $2,34 \mathrm{a}$ &, $54 \mathrm{~b}$ & $0,36 \mathrm{~b}$ & , 1256 \\
\hline 9 & 13,0 a & $2,43 \mathrm{a}$ &, $52 \mathrm{~b}$ & $0,42 \mathrm{a}$ &, 142 \\
\hline 13 & 13,0 a & $2,43 \mathrm{a}$ & $0,58 \mathrm{~b}$ & $0,42 \mathrm{a}$ & 0,1486 \\
\hline 4 & $14,0 \mathrm{a}$ & 2,46 a & ,64 a & 0,39 a & 0144 \\
\hline 5 & 13,0 a & 2,26 a & $51 \mathrm{~b}$ & $0,36 \mathrm{~b}$ & 0,1228 \\
\hline & 13,5 a & $2,50 \mathrm{a}$ & $+a$ & $0,48 \mathrm{a}$ & 664 \\
\hline & 14,5 a & $2,56 \mathrm{a}$ & 70 a & 0,43 a & 1581 \\
\hline & 13,5 a & 2,39 a & & $0,35 \mathrm{~b}$ & 260 \\
\hline 011 & 13,0 a & 2,41 a & $53 \mathrm{~b}$ & $0,38 \mathrm{~b}$ & 0,1355 \\
\hline & 12,5 a & $2,30 \mathrm{a}$ & $\mathrm{b}$ & $0,34 \mathrm{~b}$ & 0,1204 \\
\hline & 13,0 a & $2,41 \mathrm{a}$ & & $6 \mathrm{~b}$ & 308 \\
\hline 7 & 13,0 a & $2,43 \mathrm{a}$ & $\mathrm{b}$ & $0,37 \mathrm{~b}$ & 0,1356 \\
\hline & 13,0 a & $2,21 \mathrm{a}$ & $\mathrm{b}$ & $0,33 \mathrm{~b}$ & 0,1181 \\
\hline & 13,0 a & 2,39 a & & $0,35 \mathrm{~b}$ & 0,1284 \\
\hline & 13,0 a & 2,35 a & $50 \mathrm{~b}$ & $0,41 \mathrm{a}$ & 0,1378 \\
\hline & 13,5 a & 2,96 a & $00 \mathrm{a}$ & 0,46 a &, 1861 \\
\hline JFV-D12 & 13,0 a & $2,17 \mathrm{a}$ & $46 \mathrm{~b}$ & $0,31 \mathrm{~b}$ & 0,1055 \\
\hline & 12,5 a & $2,26 \mathrm{a}$ & $46 \mathrm{~b}$ & $0,33 \mathrm{~b}$ & 0,1164 \\
\hline UFV-B7 & 13,5 a & $2,27 \mathrm{a}$ & $5 \mathrm{~b}$ & $0,34 \mathrm{~b}$ & 0,1184 \\
\hline EST & 13,5 a & $2,37 \mathrm{a}$ & & $0,36 \mathrm{~b}$ & 0,1275 \\
\hline CV (\%) & 6,148 & 10,795 & 16,284 & 15,947 & 19,178 \\
\hline
\end{tabular}

Médias seguidas da mesma letra para cada variável não diferem estatisticamente entre si, pelo teste de Scott-Knott (5\%).

No segundo ensaio, dos 15 isolados de rizobactérias testados, seis (UFV-A4, UFV-F3, UFV-F6, UFV-I1, UFVG2, UFV-G4 e UFV-R6) demonstraram diferenças significativas de diâmetro do coleto em relação às mudastestemunha(UFV-G2, UFV F3, UFV-G4 eUFV-F6) e quatro estimularam significativamente o crescimento em altura da parte aérea das mudas. Todavia, não se observou aumento do peso de matéria seca do sistema radicular e da parte aérea das mudas. Entre esses isolados, três (UFV G2, UFV-F3 e UFV-G4) apresentaram diferenças significativas pelo índice de qualidade de Dickson, porém com valores superiores a 0,50 atingido pelas mudas-testemunha (Tabela 2).
Tabela 2 - Média da altura da parte aérea (APA), diâmetro do coleto (DC), peso de matéria seca da parte aérea (PMSPA) e de raízes (PMSR) e índice de qualidade de Dickson (IQD) do segundo ensaio de seleção de mudas de $P$. taeda aos 150 dias de semeadura.

Table 2 - Aerial part height, stem diameter aerial part and root dry matter weight and Dickson quality index averages of $\boldsymbol{P}$. taeda seedlings second selection assay, 150 days after sowing.

\begin{tabular}{|c|c|c|c|c|c|}
\hline$\overline{\text { Isolado }}$ & $\begin{array}{l}\text { APA } \\
(\mathrm{cm})\end{array}$ & $\begin{array}{c}\mathrm{DC} \\
(\mathrm{mm})\end{array}$ & $\begin{array}{l}\text { PMSPA } \\
\text { (g) }\end{array}$ & $\begin{array}{l}\text { PMSR } \\
\text { (g) }\end{array}$ & IQD \\
\hline$\overline{\text { UFV-A4 }}$ & $20,0 \mathrm{~b}$ & $2,89 \mathrm{~b}$ & 0,96 a & $0,38 \mathrm{a}$ & $\overline{0,5082 \mathrm{a}}$ \\
\hline UFV-AF5 & $19,0 \mathrm{~b}$ & $2,60 \mathrm{c}$ & 1,12 а & 0,46 a & 0,5550 a \\
\hline UFV-AL5 & $18,5 \mathrm{~b}$ & $2,64 \mathrm{c}$ & 1,06 a & 0,45 a & 0,6163 a \\
\hline UFV-AM1 & $19,0 \mathrm{~b}$ & $2,71 \mathrm{c}$ & 1,14 a & 0,47 a & 0,5725 a \\
\hline UFV-F3 & 21,0 a & $3.05 \mathrm{a}$ & 1,16 a & 0,46 a & $0,6161 \mathrm{a}$ \\
\hline UFV-F6 & 20,5 a & $2.95 \mathrm{~b}$ & $1,10 \mathrm{a}$ & 0,38 a & $0,4936 \mathrm{a}$ \\
\hline UFV-G2 & 21,5 a & $3.17 \mathrm{a}$ & 1,26 а & 0,43 a & 0,5513 \\
\hline UFV-G4 & 20,5 a & $2.99 \mathrm{~b}$ & 1,10 a & 0,39 a & 0,5132 a \\
\hline UFV-H2 & $19,0 \mathrm{~b}$ & $2,65 \mathrm{c}$ & $1,14 \mathrm{a}$ & 0,49 а & 0,6676 a \\
\hline UFV-K3 & $19,0 \mathrm{~b}$ & $2,73 \mathrm{c}$ & 1,18 a & 0,45 a & 0,6019 a \\
\hline UFV-N3 & $17,5 \mathrm{~b}$ & $2,50 \mathrm{c}$ & 1,05 a & 0,39 a & 0,5182 a \\
\hline UFV-P2 & $18,5 \mathrm{~b}$ & $2,65 \mathrm{c}$ & 1,07 a & $0,47 \mathrm{a}$ & $0,6504 \mathrm{a}$ \\
\hline UFV-P5 & $18,5 \mathrm{~b}$ & $2,37 \mathrm{c}$ & 0,91 a & 0,35 a & $0,4679 \mathrm{a}$ \\
\hline UFV-Q2 & $18,0 \mathrm{~b}$ & $2,62 \mathrm{c}$ & 1,07 a & 0,47 a & 0,6071 a \\
\hline UFV-R6 & $19,0 \mathrm{~b}$ & $2,87 \mathrm{~b}$ & 1,24 a & $0,47 \mathrm{a}$ & $0,6250 \mathrm{a}$ \\
\hline TEST & $18,5 \mathrm{~b}$ & $2,75 \mathrm{c}$ & 0,91 а & 0,37 a & 0,5056 a \\
\hline CV (\%) & 6,577 & 8,955 & 19,616 & 21,987 & 24,414 \\
\hline
\end{tabular}

Médias seguidas da mesma letra para cada variável não diferem estatisticamente entre si, pelo teste de Scott-Knott (5\%).

No terceiro ensaio, dos 35 isolados testados, três (UFV-AM2, UFV-AL9 e UFV AM5) contribuíram significativamente para o aumento do crescimento em altura da parte aérea das mudas e do índice de qualidade de Dickson, em relação às mudas-testemunha (Tabela 3). Não foram observadas diferenças significativas quanto ao diâmetro do coleto e peso da matéria seca da parte aérea e do sistema radicular das mudas de $P$. taeda.

No quarto ensaio, nenhum dos 24 isolados testados promoveu influência positiva no crescimento em altura da parte aérea das mudas. No entanto, nas mudas desenvolvidas em substrato contendo 15 isolados (UFVAC1, UFV-AE2, UFV-Y3, UFV-I1, UFV-I6, UFV-Ai4, UFVAJ3, UFV-J8, UFV-O6, UFV-J3, UFV-X2, UFV-T3, UFVU1, UFV-V5 e UFV-K2) foram observados o aumento do diâmetro do coleto em relação às mudas-testemunha, em oito isolados (UFV-AC1, UFV-AE2, UFV-Y3, UFVI1, UFV-I6, UFV-Ai4, UFV-X2 e UFV-K2); o aumento do peso de matéria seca da parte aérea; e em 10 (UFVAC1, UFV-AE2, UFV-I1, UFV-Ai4, UFV-AJ3, UFV-J8, UFV-U1, UFV-T3 e UFV-L3), o aumento do peso de matéria seca do sistema radicular (Tabela 4). 
Tabela 3 - Média da altura da parte aérea (APA), diâmetro do coleto (DC), peso de matéria seca da parte aérea (PMSPA) e de raízes (PMSR) e índice de qualidade de Dickson (IQD) do terceiro ensaio de seleção de mudas de $P$. taeda aos 150 dias de semeadura.

Table 3 - Aerial part height, stem diameter, aerial part and root dry matter weight and Dickson quality Index averages of $\boldsymbol{P}$. taeda seedlings third selection assay, 150 days after sowing.

\begin{tabular}{|c|c|c|c|c|c|}
\hline & $\begin{array}{l}\text { APA } \\
(\mathrm{cm})\end{array}$ & $\begin{array}{c}\mathrm{DC} \\
(\mathrm{mm})\end{array}$ & $\begin{array}{l}\text { MSPA } \\
\text { (g) }\end{array}$ & $\begin{array}{c}\text { PMSR } \\
\text { (g) }\end{array}$ & \\
\hline & $0 \mathrm{~b}$ & $36 \mathrm{a}$ & a & $\mathrm{a}$ & \\
\hline & 0 & & & & \\
\hline & & & & & \\
\hline & 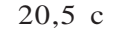 & 12 & b & & \\
\hline & 0 & $1 \mathrm{c}$ & & b & \\
\hline & , 0 с & $36 \mathrm{c}$ & & b & \\
\hline & $5 \mathrm{c}$ & $42 \mathrm{a}$ & $2 a$ & & \\
\hline & 0 & $1 \mathrm{a}$ & 5 a & $a$ & \\
\hline & , 0 & $1 \mathrm{a}$ & & & \\
\hline & ,5 c & $1 \mathrm{a}$ & & & \\
\hline & $0 \mathrm{c}$ & $2 a$ & & & \\
\hline & $0 \mathrm{~b}$ & a & & & \\
\hline & 0 & & & & \\
\hline & $5 \mathrm{c}$ & & & & \\
\hline & $5 \mathrm{c}$ & & & & \\
\hline & $5 \mathrm{c}$ & & & & \\
\hline & , 0 c & & & & \\
\hline & $0 \mathrm{~b}$ & & & & \\
\hline & & & & & \\
\hline & & & & & \\
\hline & & & & & \\
\hline & $0 \mathrm{c}$ & & & & \\
\hline & $5 \mathrm{c}$ & & & & \\
\hline & $0 \mathrm{c}$ & & & & \\
\hline & $5 \mathrm{c}$ & & & & \\
\hline & $22,0 \mathrm{c}$ & & & & 5 \\
\hline & 21,5 c & & & & \\
\hline & $0 \mathrm{c}$ & $0 \mathrm{a}$ & & & \\
\hline & $21,0 \mathrm{c}$ & $7 \mathrm{c}$ & & & 0 \\
\hline & $22,0 \mathrm{c}$ & & & & 8 \\
\hline & 22,5 c & $7 \mathrm{~b}$ & & & 6 \\
\hline & $22,0 \mathrm{c}$ & 0 a & 7 a & 7 a & 5 \\
\hline & 24,0 a & $0 \mathrm{~b}$ & & & \\
\hline & 25,0 a & 7 a & & & 2 \\
\hline & 25,5 a & & & & \\
\hline & $23,01 \mathrm{~b}$ & 3,3 & & & \\
\hline $\mathrm{FV}(\%)$ & 6,833 & 6,339 & 6,321 & 11,661 & 14,46 \\
\hline
\end{tabular}

Médias seguidas da mesma letra para cada variável não diferem estatisticamente entre si, pelo teste de Scott-Knott (5\%).

Neste estudo presente estudo, comprovou-se a promoção de crescimento de mudas de $P$. taeda, quando o substrato foi inoculado com isolados de rizobactérias promotoras do crescimento de plantas.
Tabela 4 - Média da altura da parte aérea (APA), diâmetro do coleto (DC), peso de matéria seca da parte aérea (PMSPA) e de raízes (PMSR) e índice de qualidade de Dickson (IQD) do quarto ensaio de seleção de mudas de $P$. taeda aos 150 dias de semeadura

Table 4 - Aerial part height, stem diameter, aerial part and root dry matter weight and Dickson quality index averages of $\boldsymbol{P}$. taeda seedlings fourth selection assay, 150 days after sowing

\begin{tabular}{|c|c|c|c|c|c|}
\hline & $\begin{array}{l}\text { APA } \\
(\mathrm{cm})\end{array}$ & $\begin{array}{c}\text { DC } \\
(\mathrm{mm})\end{array}$ & $\begin{array}{l}\text { MSPA } \\
\text { (g) }\end{array}$ & $\begin{array}{c}\text { PMSR } \\
\text { (g) }\end{array}$ & \\
\hline V-A & 0 & 54 b & 1 & 54 a & \\
\hline FV- & 0 & 0 & 47 & 58 a & \\
\hline F-A & 0 a & 79 & $43 \mathrm{a}$ & 55 a & 58 \\
\hline $\mathrm{V}-\mathrm{AI}$ & 5 a & $67 \mathrm{~b}$ & 12 b & $38 \mathrm{~b}$ & 78 \\
\hline EV-A & $5 \mathrm{a}$ & $64 \mathrm{~b}$ & 08 b & $50 \mathrm{~b}$ & 56 \\
\hline $\mathrm{V}-$ & 0 a & 03 a & $40 \mathrm{a}$ & $62 \mathrm{a}$ & 83 \\
\hline$E V-A$ & 0 a & 86 a & 17 b & $62 \mathrm{a}$ & 75 \\
\hline F-I1 & 0 a & 86 a & 42 a & 62 a & 45 \\
\hline V-I6 & $0 \mathrm{a}$ & 85 a & $\mathrm{a}$ & & $=0$ \\
\hline & & 00 a & & & 23 \\
\hline & & 78 а & & & 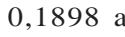 \\
\hline V-K2 & 5 a & 01 a & & & 04 \\
\hline $\mathrm{L} 2$ & 0 & & & & 27 \\
\hline 3 & & & & & 05 \\
\hline & & & & & 02 \\
\hline & & & & & 20 \\
\hline & & & & & 49 \\
\hline & a & 9 a & & & 34 \\
\hline & & 8 a & & & 73 \\
\hline & & $1 \mathrm{~b}$ & & & 9 \\
\hline & 19,5 а & 2,80 a & $2 \mathrm{~b}$ & $9 \mathrm{~b}$ & 00 \\
\hline $\mathrm{V}-\mathrm{X} 2$ & 21,0 a & 2,98 a & & & 55 \\
\hline V-Y3 & 20,0 a & $2,88 \mathrm{a}$ & & & 95 \\
\hline V-Y7 & 20,0 a & $2,62 \mathrm{~b}$ & & $4 \mathrm{~b}$ & 574 \\
\hline 1 & 20,5 a & $2,66 \mathrm{~b}$ & & $0,44 \mathrm{~b}$ & 15 \\
\hline $\mathrm{CV}(\%)$ & 6,344 & 8,172 & 14,859 & 18,005 & \\
\hline
\end{tabular}

Médias seguidas da mesma letra para cada variável não diferem estatisticamente entre si, pelo teste de Scott-Knott (5\%).

A seleção dos melhores isolados foi estabelecida e baseada em médias de altura da parte aérea, que diferenciaram significativamente das mudas-testemunha e apresentaram índice de qualidade de Dickson acima do preestabelecido. Os isolados que não foram selecionados poderão ser utilizados em testes futuros.

Entre os 99 isolados testados nos ensaios de seleção, seis (UFV-AL9, UFV-AM5, UFV-AM2, UFV-F3, UFVG2 e UFV-G4) influenciaram positivamente na qualidade das mudas, ou seja, cerca de $6 \%$ do total de isolados de rizobactérias apresentaram efeitos de PGPR. Esses resultados estão compatíveis com os dados obtidos por Teixeira (2001), que constatou que aproximadamente 
$10 \%$ dos isolados obtidos da rizosfera de eucalipto foram eficientes quanto à indução da rizogênese e à promoção de crescimento de mudas.

Em outros trabalhos de seleção de isolados para outras culturas, o porcentual de rizobactérias benéficas variaram de 1 a 5\% (KLOEPPER et al., 1980; BURR e CAESAR, 1984). Embora ainda não se conheçam as causas dessas variações, acredita-se que o uso de substrato obtido de compostagem, utilizado para produção das mudas, possa favorecer a predominância de microrganismos benéficos, incluindo as rizobactérias (HOITINK; FAHY, 1986; TEIXEIRA, 2001).

A maioria das rizobactérias benéficas isoladas pertence aos gêneros Pseudomonas e Bacillus e com menor frequência nos gêneros Azotobacter, Arthrobacter, Clostridium, Hydrogenophaga, Enterobacter, Serratia e Azospirillum, entre outros (BENIZRI et al., 2001).

Em estudos conduzidos por Shishido et al. (1995) e por Bal e Chanway (2000), foram obtidos isolados dos gêneros Bacillus e Paenibacillus, a partir de solo da rizosfera de mudas e de florestas de $P$. contorta var latifolia (Dougl.) Engelm.

As menores médias observadas em mudas do primeiro e segundo ensaios podem ser explicadas em função da época de semeadura e do fato de desenvolvimento das mudas ter ocorrido em períodos mais frios, devendo ser ressaltado que as mudas do terceiro e quarto ensaios de seleção ocorreram em período mais quente. Segundo Carneiro (1995), o ideal é que as sementes de Pinus sp. sejam semeadas na primavera, geralmente na segunda quinzena de setembro até final de outubro. Nessa época, a velocidade de emergência de plântulas é maior e o risco de ataque de fungos patogênicos, menor (ENEBAK et al., 1998). Considerando que ocorram melhores condições para o crescimento e desenvolvimento das plantas, espera-se que haja também maior efeito da aplicação de rizobactérias benéficas.

A aplicação de diferentes isolados de rizobactérias, em especial os da terceira seleção no substrato para produção de mudas de $P$. taeda, resultou no aumento da altura da parte aérea das plantas e dos pesos de matéria seca de raiz e da parte aérea. Segundo Carneiro (1995), a altura de mudas não deve ser considerada como variável isolada para expressar a qualidade de mudas, principalmente se não houver equilíbrio adequado entre a parte aérea e o sistema radicular.Assim, empregou-se o índice de qualidade de Dickson (DICKSON et al., 1960), por ser capaz de predizer a qualidade das mudas antes de seu plantio definitivo no campo. O índice é uma combinação de variáveis morfológicas e quanto maior o seu valor, melhor a qualidade das mudas. Hunt (1990) recomendou o índice de qualidade de Dickson (IQD) e, com base em resultados de trabalhos de pesquisa, estabeleceu o valor mínimo de 0,20 como bom indicador da qualidade das mudas de Pseudotsuga menziesii (Mirb.) Franco (douglas-fir) e Picea abies L. (norwayspruce), crescidas em recipientes com capacidade para 50 ou $60 \mathrm{~mL}$. Neste trabalho foram encontrados valores bem superiores a esse índice, apesar de não ter ocorrido diferença significativa nas mudas desenvolvidas na presença de seis isolados utilizados.

Esses isolados foram selecionados para a realização de estudos futuros que procurarão viabilizar o uso comercial de rizobactérias promotoras do crescimento para produção de mudas de Pinus.

\section{CONCLUSÕES}

Os resultados deste trabalho permitiram concluir que, entre as 99 rizobactérias testadas, os isolados UFV-AM5, UFV-AM2, UFV-G2, UFV-G4, UFV-F3 e UFVAL9 foram selecionados por promoverem ganhos que variaram de 10 a $16 \%$ no crescimento em altura da parte aérea das mudas e por apresentarem índice de qualidade de Dickson entre 0,19 e 0,61.

\section{REFERÊNCIAS}

ASSOCIAÇÃO BRASILEIRA DE PRODUTORES DE FLORESTAS PLANTADAS - ABRAF. 2009. Anuário estatístico da ABRAF: ano base 2008. Brasília: 2008. 129p.

BAL, A. S.; CHANWAY, C. P. Isolation and identification of endophytic bacteria from lodge pole pine and western red cedar. In: INTERNATIONAL PGPR WORKSHOP, 5., 2000, Cordoba. Proceedings... Cordoba: 2000.

BENIZRI, E.; BAUDOIN, E.; GUCKERT, A. Root colonization by inoculated plant growth-promoting rhizobacteria. Biocontrol Science and Technology, v.11, p. 557 574, 2001.

BENT, E. et al.. Surface colonization of lodgepole pine (Pinus contorta var. latifolia [Dougl. Engelm.]) roots by Pseudomonas fluorescens and Paenibacillus polymyxa under gnotobiotic conditions. Plant and Soil, v.241, n.1 p.187-196, 2002. 
BENT, E.; TUZUN, S.; CHANWAY, C. P.; ENEBAK, $S$. Alterations in plant growth and in root hormone levels of lodge pole pines inoculated with rhizobacteria. Canadian Journal of Microbiology, v. 47, p. 793-800, 2001.

BURR, T. J.; CAESAR, A. Beneficial plant bacteria. Critical Reviews in Plant Science, v.2, n.1, p.1-20, 1984.

CARneiro, J. G. A. Produção e controle de qualidade de mudas florestais. Curitiba: Universidade Federal do Paraná; Campos: Universidade Estadual do Norte Fluminense, 1995. 451p.

CHANWAY, C. P. et al. Endophytic colonization and field responses of hybrid spruce seedlings after inoculation with plant growth-promoting rhizobacteria. Forest Ecology and Management, v.133, n.1, p.81-88, 2000.

DICKSON, A.; LEAF, A. L.; HOSNER, J. F. Quality appraisal of white spruce and white pine seedling stock in nurseries. Forest

Chronicle, v.36, n.1, p.10-3, 1960.

ENEBAK, S. A. Plant growth promoting rhizobacteria as an alternative treatment for methyl bromide. Auburn: Auburn University, Southern Forest Nursery Management Cooperative, 1998. p.98-104. (Research Report, 1998)

ENEBAK, S. A.; CAREY, W. A. Plant growthpromoting rhizobacteria induced systemic resistance to fusiform rust in naturally inoculated loblolly seedlings. Southern Journal of Applied Forestry, v.28, n.1, p.185-188, 2004.

EUCLYDES, R. F. Manual de utilização do programa SAEG (Sistema para Análises Estatística e Genética). Viçosa, MG: Universidade Federal de Viçosa, 1983. 59p.

FONSECA, E. P. et al. Padrão de qualidade de mudas de Trema micrantha (L.) Blume, produzidas sob diferentes períodos de sombreamento.

Revista Árvore, v.26, n.4, p.515-523, 2002.

HOITINK, H. A.; FAHY, P. C. Basis for the control of soilborne plant pathogens with composts. Annual Review

Phytopathology, v.24, n.1, p.93-114, 1986.
HUNT, R. Basic growth analysis.

London:Unwin Hyman, 1990. 112p.

KADO, C. J.; HESKETT, M. G. Selective media for isolation of Agrobacterium, Corynebacterium, Erwinia, Pseudomonas and Xanthomonas. Phytopathology, v.60, p.969-976, 1970.

KING, E. O.; WARD, M. K.; RANEY, D. E. Two simple media for the demonstration of pyocyanin and fluorescin. Journal of Laboratory and Clinical Medicine, v.44, p.301-307, 1954.

KLOEPPER, J. W.; LEONG, J.; TEINTZE, M.; SCHROTH, M. N. Enhanced plant growth by siderophores produced by plant growth-promoting rhizobacteria. Nature, v. 286, p. 885-886, 1980.

KLOEPPER, J. W.; LIFSHITZ, R.;

ZABLOTOWICZ, R. M. Free-living bacterial inocula for enhancing crop productivity. Trends in Biotechnology, v.7, n.1, p.39-44, 1989.

KRONKA, F. J. N.; BERTOLANI, F.; PONCE, R. H. A cultura do Pinus no Brasil. São Paulo, Sociedade Brasileira de Silvicultura, 2005. 160p.

KUNC, F.; MACURA, J. Mechanism of adaptation and selection of microorganism in the soil. In: VANCURA, V.; KUNC, F. (Eds.). Soil microbial association. Amesterdam: Elsevier, 1988. p.281-299.

MAFIA, R. G. et al. Crescimento de mudas e produtividade de minijardins clonais de eucalipto tratados com rizobactérias selecionadas. Revista Árvore, v.29, n.6, p.843-851, 2005

PROBANZA, A. et al. Effects of inoculation with PGPR Bacillus and Pisolithus tinctorius on Pinus pinea L. growth, bacterial rhizosphere colonization, and mycorrhizal infection. Microbial Ecology, v.41, p.140-148, 2001.

SCHROTH, M. N.; HANCOCK, J. G. Diseasesuppressive soil and root-colonizing bacteria. Science, v.216, p.1376-1381, 1982.

SHISHIDO, M.; LOEB, B. M.; CHANWAY, C. P. External and internal root colonization of lodge pole pine seedlings by two growth-promoting Bacillus strains originated from different root microsites. Canadian Journal of Microbiology, v.41, p.707-713, 1995.

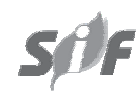

Revista Árvore, Viçosa-MG, v.34, n.3, p.399-406, 2010 
TEIXEIRA, D. A. Promoção de enraizamento e indução de resistência sistêmica à ferrugem e à mancha-de-Cylindrocladium, mediadas por rizobactérias em clones de Eucalyptus spp. 2001. 67f. Tese (Doutorado em Fitopatologia) Universidade Federal de Viçosa, Viçosa, MG 2001.
TEIXEIRA, D. A. et al. Evidências de indução de resistência sistêmica à ferrugem do eucalipto mediada por rizobactérias promotoras do crescimento de plantas. Fitopatologia Brasileira, v.30, n.4, p.350-356, 2005. 